\title{
Ameliorating Effects of Different Extracts of Culinary Mushroom Species on the Production Performance of Healthy and Eimeria Infected Commercial Broiler Birds
}

\author{
Muhammad Irfan Ullah ${ }^{1,2^{*}}$, Masood Akhtar ${ }^{1,2}$, Muhammad Irfan Anwar ${ }^{1}$, Mian Muhammad Awais ${ }^{1}$, Kashfa Khaliq ${ }^{2}$ \\ and Nabeel Ijaz ${ }^{3}$ \\ ${ }^{1}$ Department of Pathobiology, Faculty of Veterinary Sciences, Bahauddin Zakariya University Multan, Pakistan \\ ${ }^{2}$ Immunoparasitology Laboratory, Department of Parasitology, Faculty of Veterinary Sciences, University of Agriculture, \\ Faisalabad, Pakistan \\ ${ }^{3}$ Department of Clinical Sciences, Faculty of Veterinary Sciences Bahauddin Zakariya University Multan, Pakistan \\ *For correspondence: irfanullah@bzu.edu.pk; irfanullahvet@gmail.com \\ Received 28 January 2021; Accepted 02 April 2021; Published 10 June 2021
}

\begin{abstract}
In this research, three edible mushroom species including Pleurotus (P.) ostreatus, P. sajor-caju and Lentinus (L.) edodes were processed for hot water, methanolic and polysaccharide extracts. These extracts were administered to commercial broiler birds. Production performance was determined as weight gains and feed conversion ratios (FCR) in healthy birds on weekly basis. Further, groups were subjected to oral Eimeria infection and weight gains were monitored from days 4 to 12 post inoculation. Study revealed significantly higher $(P<0.05)$ weight gains in experimental groups given different mushroom extracts during $4^{\text {th }}, 5^{\text {th }}$ and $6^{\text {th }}$ weeks of experiment in comparison to control. Feed conversion ratios observed in the control groups were significantly higher $(P<0.05)$ as compared to experimental groups especially methanolic extracts of all three mushroom species during $5^{\text {th }}$ and $6^{\text {th }}$ weeks of the experiment. After Eimeria inoculation, weight gains of the experimental groups given different mushroom extracts were significantly higher $(P<0.05)$ on $10^{\text {th }}, 11^{\text {th }}$ and $12^{\text {th }}$ day. Results concluded that aqueous, methanolic and polysaccharide extracts of $P$. ostreatus, $P$. sajor-caju and L. edodes had potential to improve the production in healthy birds and may also enhance the weights in commercial broiler birds suffering from Eimeria infection. (C) 2021 Friends Science Publishers
\end{abstract}

Keywords: Eimeria; Coccidiosis; Mushroom; Production; Chicken; Broiler

\section{Introduction}

There is an increasing concern among poultry consumers regarding the irrational use of synthetic medicines in the poultry feed for prophylactic and growth promoting effects. Moreover, widespread use of antibiotics in poultry feed has resulted in rapid development of resistance against several pathogens (Cowieson and Kluenter 2019). These undesirable effects led to ban on the use of antibiotic growth promoters in the poultry feed in Europe in January 2006 (Salim et al. 2018). These restrictions caused the enteric pathogens to grow more to affect the health and production of the poultry birds. Therefore, it is needed to substitute substances from natural sources to maintain and increase production in the poultry industry. Intensified research proceeded in the last 2-3 decades for the development of certain substances that can be alternated to antibiotics for the improvement of health and production in poultry industry. Among these substances, probiotics, prebiotics, nutraceuticals, plant extracts and acidifiers were investigated (Dharma and Tomar 2007; Adhikari and Kim 2017; Abbas et al. 2020; Hazrati et al. 2020).

Coccidiosis is a major protozoal infection causing huge economic losses to the poultry producers in terms of compromised usage of feed and reduced growth rates of birds (Khater et al. 2020). Prophylactic medication to avian coccidiosis adds considerable increase in the prices of poultry feed (Lillehoj et al. 2004). Additionally, growth promoters are also commonly used in the poultry feed to exploit the production potential of genetically engineered birds. Different types of growth promoters including probiotics, prebiotics, enzymes, antioxidants and coccidiostats are being used in poultry industry (Angelakis et al. 2013). In case of withdrawal of these agents from the poultry feed, productive performance of the poultry birds severely affects the production parameters along with increasing the vulnerability of the birds towards different diseases (Yasmin et al. 2020).

To cite this paper: Ullah MI, M Akhtar, MI Anwar, MM Awais, K Khaliq, N Ijaz (2021). Ameliorating effects of different extracts of culinary mushroom species on the production performance of healthy and Eimeria infected commercial broiler birds. Intl J Agric Biol 26:39-44 
Different mushrooms have been reported to possess growth promoting and therapeutic activities against several ailments (Willis et al. 2012, 2013; Gargano et al. 2017). Mushrooms have dietary priority over other sources from plant origin because of higher contents of good quality protein, dietary fibres and vitamin B with less fat and no cholesterol (Ghorai et al. 2009). Exudate secreted from the cell surface of mycelia of mushrooms contains natural antibiotics and some of these antibiotics target specific pathogens (Willis et al. 2009).

Keeping in view the beneficial effects of mushrooms, present study was designed to investigate the effects of extracts obtained from different culinary mushroom species on the production performance of healthy as well as commercially grown broiler birds infected experimentally with Eimeria.

\section{Materials and Methods}

\section{Preparation of methanolic and polysaccharide extracts}

Mushroom species including Pleurotus ostreatus (PO), P. sajor-caju (PSC) and Lentinus edodes (LE) procured from the local grower in Millat Town Faisalabad were identified (Voucher no. 173 (LE), 174 (PO) \& 175 (PSC), dried, pulverized and sieved. All three mushroom species were processed for hot water extract (HWE), methanolic extract (ME) and polysaccharide extract (PSE). For HWE, mushroom powder $(500 \mathrm{~g})$ was added in $1500 \mathrm{~mL}$ of distilled water and stirred followed by boiling (4 h), centrifugation (3000 rpm for $30 \mathrm{~min}$ ) and lyophilization. For ME, mushroom powder (500 g) was added in $1000 \mathrm{~mL}$ of $80 \%$ methanol and vortexed for $24 \mathrm{~h}$ followed by rotary evaporation and lyophilization. For PSE, mushroom powder (200 g) added in 95\% ethanol for $24 \mathrm{~h}$ followed by ultrasonication, centrifugation (4000 $\mathrm{rpm} / 30 \mathrm{~min})$ and washing with ethanol, acetone and ether. Crude extract thus obtained was fractionated through diethylaminoethyl (DEAE-52) cellulose column followed by Sephadex G-100 columns to obtain polysaccharide extracts (Ullah et al. 2014).

\section{Preparation of mixed species Eimeria infection}

Intestines of the broiler birds were collected from the butcher shops and poultry farms around Faisalabad. After direct microscopic examination of the intestinal contents, positive samples were separated and contents were squeezed to collect the infected material. Equal quantity of 2.5 per cent $\mathrm{K}_{2} \mathrm{Cr}_{2} \mathrm{O}_{7}$ added to the contents having mixed species of Eimeria (for 48-72 h). The mixture was centrifuged at 1500 rpm for $10 \mathrm{~min}$. Sediment thus obtained was processed for $\mathrm{ZnSO}_{4}$ floatation technique. Supernatant thus collected was washed with PBS three times and challenged dose was adjusted at 6.5-7.0 × 10 $0^{4}$ sporulated oocyst (Mumtaz et al. 2021).

\section{Experimental design}

Present study was divided into two experiments. In the experiment 1, HWE and ME, of LE, PO and PSC mushrooms were investigated. Briefly, a total of 350 birds were kept at experiment station of Parasitology Department, University of Agriculture-Faisalabad Pakistan. After 5 days, acclimatized birds were divided randomly into $7 \quad(n=50)$ groups and given mushroom extracts on day $7^{\text {th }}, 8^{\text {th }}$ and $9^{\text {th }}$ of the experiment. In the experiment 2, PSE of LE, PO and PSC were investigated for production performance of broiler birds. A total of 200-day old birds were kept in the experiment station of Microbiology Department Veterinary Sciences Faculty University of Agriculture Faisalabad. On day $5^{\text {th }}$, birds were divided into $4(\mathrm{n}=50)$ groups and given PSE on day $7^{\text {th }}, 8^{\text {th }} 9^{\text {th }}$ (Table 1) Experimental groups assigned were given different mushroom extracts dissolved in PBS (Phosphate Buffer Saline) as solvent. However, control groups of both experiments were given $2 \mathrm{~mL}$ of PBS.

In both experiments, following routine vaccination schedule for Newcastle Disease, Infectious Bursal Disease and Hydropericardium Syndrome was done and birds were offered withdrawal feed and water ad-libitum. All the experimental groups including controls were given mixed specie Eimeria infection orally, on day $21^{\text {st }}$ of the experiment at the dose rate of 6.5-7.0 $\times 10^{4}$ oocysts/bird.

\section{Weight gains and feed conversion ratios (FCR) of healthy birds}

Birds belonging to all groups from $1^{\text {st }}$ and $2^{\text {nd }}$ experiments were kept in separate cages and monitored for feed consumption and weight gains weekly for up to 6 weeks of age and similarly, feed conversion ratios (FCR) were also calculated by using the following formula:

$$
F C R=\frac{\text { Total feed consumed }(\mathrm{gms})}{\text { Total weight gains }(\mathrm{gms})}
$$

\section{Weight gains post experimentally induced Eimeria infected birds}

Half of birds from all experimental and control groups were separated in both $1^{\text {st }} \& 2^{\text {nd }}$ experiments and were given mixed specie infection of Eimeria at the dose rate of $\left(6.5-7.0 \times 10^{4}\right)$ sporulated oocysts on day $21^{\text {st }}$ of the experiment and weights were recorded from day $4^{\text {th }}$ to day $12^{\text {th }}$ post Eimeria challenge. Oocysts per gram of feces, lesion scoring, and mortality percentages were also calculated (Ullah et al. 2014. 2015, 2018a, b).

\section{Statistical analysis}

Data obtained in the experiments was subjected to S.P.S.S. v. 21 and Tuckey's range test was used for one-way ANOVA to determine the differences among various groups at $P<0.05$. 
Improvement in Broiler Production by using Mushroom Extracts / Intl J Agric Biol, Vol 26, No 1, 2021

\section{Results}

\section{Experiment 1}

Weekly weight gains: In the experiment 1 , birds from all groups were weighed and feed consumed by each group was noted during $1^{\text {st }}$ to $6^{\text {th }}$ weeks of the experiment. Groups given Hot Water Extracts (HWE) and Methanolic Extracts (ME) of P. ostreatus (PO), L. edodes (LE) and P. sajor-caju (PSC), respectively showed significantly higher $(P<0.05)$ body weights as compared to control during the last three weeks $\left(4^{\text {th }}, 5^{\text {th }}\right.$ and $\left.6^{\text {th }}\right)$ of the experiment. In the $4^{\text {th }}$ week of the experiment, among different groups highest weights $(\mathrm{g})$ were observed in group given ME of LE (1016) followed by HWE of LE (967), ME of PSC (950), ME of PO (910), HWE of PSC (892) and HWE of PO (858). In the $5^{\text {th }}$ week, highest weights were observed in the ME of LE (1396) followed by ME of PSC (1295), HWE of LO (1253), ME of PO (1238), HWE of PSC (1218) and HWE of PO (1140). In the last week of the experiment, Maximum weights were observed in HWE and ME of LE $(1722,1669)$ followed by PSC $(1631,1608)$ and PO $(1610,1555)$, respectively (Table 2).

Feed conversion ratios (FCR): In control group, FCR observed during $6^{\text {th }}$ weeks of the experiment was significantly higher $(P<0.05)$ as compared to groups treated with HWE of LE, PSC and ME of PO, LE and PSC. In $5^{\text {th }}$ week of the experiment, groups given ME of LE and PSC showed significantly higher $(P<0.05)$ performance in terms of FCR as compared to control. In $4^{\text {th }}$ and $2^{\text {nd }}$ weeks of experiment, groups given ME of all three mushroom species showed significantly better performance in FCR. Among different experimental groups, groups administered with ME of LE showed better performance followed by ME of PSC and PO (Fig. 1).

Weight gains post Eimeria infection: The experimental and control groups were subjected to infective dose of Eimeria and weight gains were monitored from day $4^{\text {th }}$ to day $12^{\text {th }}$ post Eimeria infection. In the experiment 1 , on day $6^{\text {th }}, 10^{\text {th }}$ and $11^{\text {th }}$ weight gains observed in all experiment groups were statistically higher $(P<0.05)$ as compared to control. Among different groups, in most of the days highest weights post infection were observed in ME and HWE of LE followed by ME and HWE of PSC and PO, respectively (Fig. 2).

\section{Experiment 2}

Weekly weight gains: Polysaccharide extracts (PSE) of PO, LE and PSC were evaluated in term of weekly weight gains. Weights $(\mathrm{g})$ observed during $5^{\text {th }}$ and $6^{\text {th }}$ weeks of the experiment were significantly higher $(P<0.05)$ in PSE of PO, LE and PSC. Among the mushroom treated groups in the $5^{\text {th }}$ week of the experiment, highest weights $(\mathrm{g})$ were observed in PSE of LE (1352) followed by PO (1335) and PSC (1272). During $6^{\text {th }}$ week of the experiment, highest weights were observed in PSE of LE (1851) followed by PO
Table 1: Different treatment groups assigned in Experiment 1 and 2

Experiment 1: $\quad$ Experiment 2:

G1: HWE of PO @ $200 \mathrm{mg} / \mathrm{kg}$ B.Wt. G1a: PSE of PO @ $25 \mathrm{mg} / \mathrm{kg}$ B. Wt. G2: HWE of LE @ $200 \mathrm{mg} / \mathrm{kg}$ B.Wt. G2b: PSE of LE @ $25 \mathrm{mg} / \mathrm{kg} \mathrm{B}$. Wt. G3: HWE of PSC @ 200mg/kg B.wt. G3c: PSE of PSC @ $25 \mathrm{mg} / \mathrm{kg}$ B. Wt. G4: ME of PO @ @ 200mg/kg B.wt. G4d: Control: 2 mL PBS saline G5: ME of LE @ $200 \mathrm{mg} / \mathrm{kg} \mathrm{B}$.wt.

G6: ME of PSC@ $200 \mathrm{mg} / \mathrm{kg}$ B. wt.

G7: Control: $2 \mathrm{~mL}$ PBS saline

HWE=Hot water Extract, ME=Methanol extract, $\mathrm{PSE}=$ Polysaccharide extract, $\mathrm{PO}=$ Pleurotus ostreatus, $\mathrm{LE}=$ Lentinus edodes, $\mathrm{PSC}=$ Pleurotus sajor-caju, $\mathrm{B}$. Wt. $=$ Body Weight

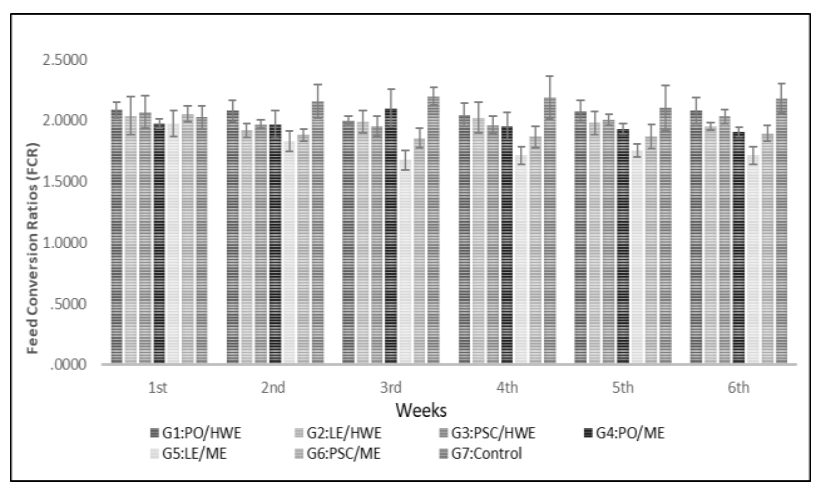

Fig. 1: Weekly feed conversion ratios (FCR) of experimental and control groups in experiment 1.

$\mathrm{PO}=$ Pleurotus ostreatus, $\mathrm{LE}=$ Lentinus edodes, $\mathrm{PSC}=$ Pleurotus sajor-caju, $\mathrm{HWE}=\mathrm{Hot}$ Water Extract, $\mathrm{ME}=$ Methanol Extract. G1: Hot water extract of Pleurotus ostreatus administered @ $200 \mathrm{mg} / \mathrm{kg}$ body weight. G2: Hot water extract of Lentinus edodes administered @ $200 \mathrm{mg} / \mathrm{kg}$ body weight. G3: Hot water extract of Pleurotus sajor-caju administered @ $200 \mathrm{mg} / \mathrm{kg}$ body weight. G4: Methanolic extract of Pleurotus ostreatus administered @ $200 \mathrm{mg} / \mathrm{kg}$ body weight. G5: Methanolic extract of Lentinus edodes administered @ $200 \mathrm{mg} / \mathrm{kg}$ body weight. G6: Methanolic extract of Pleurotus sajorcaju administered @ $200 \mathrm{mg} / \mathrm{kg}$ body weight. G7: Control

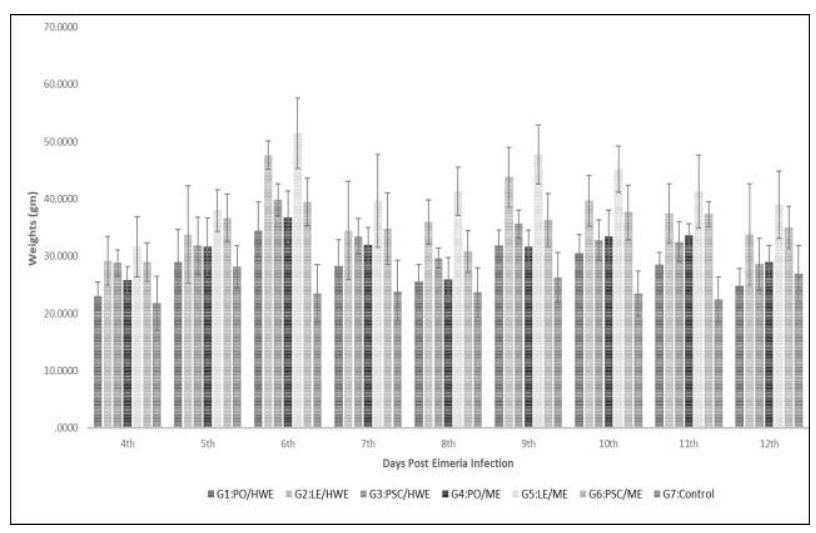

Fig. 2: Weight gains of experimental and control groups post Eimeria infection in experiment 1.

$\mathrm{PO}=$ Pleurotus ostreatus, $\mathrm{LE}=$ Lentinus edodes, $\mathrm{PSC}=$ Pleurotus sajor-caju, $\mathrm{HWE}=\mathrm{Hot}$ Water Extract, $\mathrm{ME}=$ Methanol Extract. G1: Hot water extract of Pleurotus ostreatus administered @ $200 \mathrm{mg} / \mathrm{kg}$ body weight. G2: Hot water extract of Lentinus edodes administered @ $200 \mathrm{mg} / \mathrm{kg}$ body weight. G3: Hot water extract of Pleurotus sajor-caju administered @ $200 \mathrm{mg} / \mathrm{kg}$ body weight. G4: Methanolic extract of Pleurotus ostreatus administered @ $200 \mathrm{mg} / \mathrm{kg}$ body weight. G5: Methanolic extract of Lentinus edodes administered @ $200 \mathrm{mg} / \mathrm{kg}$ body weight. G6: Methanolic extract of Pleurotus sajorcaju administered @ $200 \mathrm{mg} / \mathrm{kg}$ body weight G7: Control

(1820) and PSC (1580), respectively (Table 3).

Feed conversion ratios: FCR observed in control groups 
Ullah et al. / Intl J Agric Biol, Vol 26, No 1, 2021

Table 2: Weekly weight gains (g) in experimental and control groups (Experiment 1)

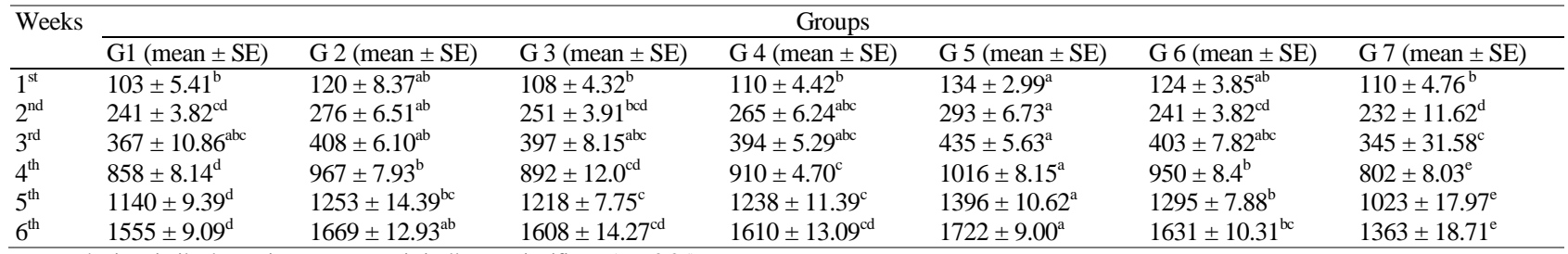

Means sharing similar letters in a row are statistically non-significant $(P>0.05)$.

G1: Hot water extract of Pleurotus ostreatus administered @ $200 \mathrm{mg} / \mathrm{kg}$ body weight. G2: Hot water extract of Lentinus edodes administered @ 200 mg /kg body weight. G3: Hot water extract of Pleurotus sajor-caju administered @ $200 \mathrm{mg} / \mathrm{kg}$ body weight. G4: Methanolic extract of Pleurotus ostreatus administered @ 200 mg/kg body weight. G5: Methanolic extract of Lentinus edodes administered @ $200 \mathrm{mg} / \mathrm{kg}$ body weight. G6: Methanolic extract of Pleurotus sajor-caju administered @ $200 \mathrm{mg} / \mathrm{kg}$ body weight. G7: Control

Table 3: Weekly weight gains (g) in experimental and control groups (Experiment 2)

\begin{tabular}{|c|c|c|c|c|}
\hline \multirow[t]{2}{*}{ Weeks } & \multicolumn{4}{|c|}{ Groups } \\
\hline & G1a $($ mean \pm SE) & G1b $($ mean \pm SE $)$ & G1c $($ mean \pm SE $)$ & G1d $($ mean $\pm \mathrm{SE})$ \\
\hline $1^{\text {st }}$ & $104 \pm 3.15^{\mathrm{b}}$ & $124 \pm 2.95^{\mathrm{a}}$ & $97 \pm 2.197^{b}$ & $85 \pm 2.07^{\mathrm{c}}$ \\
\hline $2^{\text {nd }}$ & $212 \pm 5.72^{b}$ & $253 \pm 3.45^{\mathrm{a}}$ & $209 \pm 7.03^{b c}$ & $187 \pm 5.71^{\mathrm{c}}$ \\
\hline $4^{\text {th }}$ & $920 \pm 6.85^{b c}$ & $1001 \pm 7.07^{\mathrm{a}}$ & $943 \pm 16.76^{b}$ & $884 \pm 18.87^{\mathrm{c}}$ \\
\hline $5^{\text {th }}$ & $1335 \pm 12.35^{\mathrm{ab}}$ & $1352 \pm 10.38^{\mathrm{a}}$ & $1272 \pm 16.10^{\mathrm{b}}$ & $1059 \pm 24.09^{c}$ \\
\hline $6^{\text {th }}$ & $1820 \pm 16.15^{\mathrm{a}}$ & $1851 \pm 10.41^{\mathrm{a}}$ & $1580 \pm 11.40^{\mathrm{b}}$ & $1411 \pm 13.04^{\mathrm{c}}$ \\
\hline
\end{tabular}

Means sharing similar letters in a row are statistically non-significant $(P>0.05)$

G1a: Polysaccharide Extract of Pleurotus ostreatus administered @ $25 \mathrm{mg} / \mathrm{kg}$ body weight. G1b: Polysaccharide Extract of Lentinus edodes administered @ 25 mg /kg body weight. G1c: Polysaccharide Extract of Pleurotus sajor-caju administered @ $25 \mathrm{mg} / \mathrm{kg}$ body weight. G1d: Control

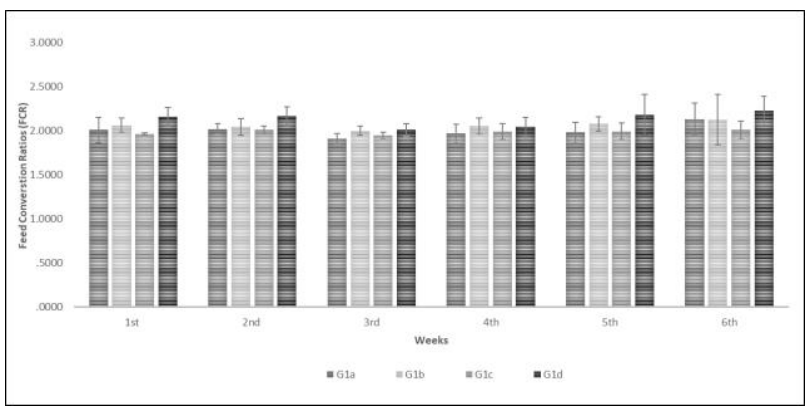

Fig. 3: Weekly Feed Conversion Ratios (FCR) of experimental and control groups in experiment 2

$\mathrm{PO}=$ Pleurotus ostreatus, $\mathrm{LE}=$ Lentinus edodes, $\mathrm{PSC}=$ Pleurotus sajor -caju, $\mathrm{PSE}=$ Polysaccharide Extract. G1a: Polysaccharide Extract of Pleurotus ostreatus administered @ $25 \mathrm{mg} / \mathrm{kg}$ body weight. Glb: Polysaccharide Extract of Lentinus edodes administered @ $25 \mathrm{mg} / \mathrm{kg}$ body weight. G1c: Polysaccharide Extract of Pleurotus sajor-caju administered @ $25 \mathrm{mg} / \mathrm{kg}$ body weight. G1d: Control

were statistically non-significant $(P>0.05)$ as compared to all experimental groups during $6^{\text {th }}, 5^{\text {th }}$ and $4^{\text {th }}$ week of the experiment. However, during $3^{\text {rd }}$ week, FCR observed in group given PSE of PO and in the $2^{\text {nd }}$ week, groups given PSE of PO and PSC showed significant improvement in FCR as compared to control (Fig. 3).

Weight gains post Eimeria infection: On day $7^{\text {th }}, 11^{\text {th }}$ and $12^{\text {th }}$ weight gains observed in the experimental groups were statistically higher $(P<0.05)$ as compared to control. Among different experimental groups, in most of the days highest weight gains were observed in PSE of LE followed by PO and PSC (Fig. 4).

\section{Discussion}

In production animals, growth augmentation due to the feeding of nondigestible carbohydrates, terpenes, tannins,

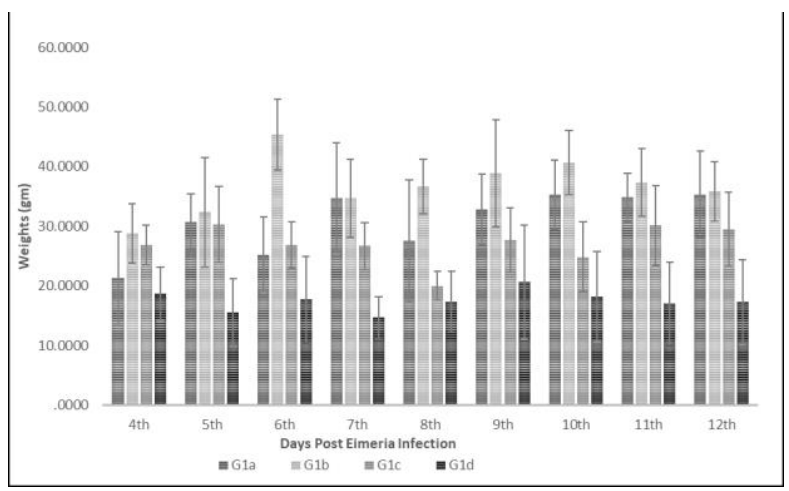

Fig. 4: Weight gains of experimental and control groups post Eimeria infection in experiment 2.

$\mathrm{PO}=$ Pleurotus ostreatus, $\mathrm{LE}=$ Lentinus edodes, $\mathrm{PSC}=$ Pleurotus sajor-caju, $\mathrm{PSE}=$ Polysaccharide Extract. G1a: Polysaccharide Extract of Pleurotus ostreatus administered @ $25 \mathrm{mg} / \mathrm{kg}$ body weight. G1b: Polysaccharide Extract of Lentinus edodes administered @ $25 \mathrm{mg} / \mathrm{kg}$ body weight. G1c: Polysaccharide Extract of Pleurotus sajor-caju administered @ $25 \mathrm{mg} / \mathrm{kg}$ body weight. G1d: Control

flavonoids, saponins, alkaloids, phenolics, resins and minerals from plant source is well reported (Stanley et al. 1997; Grizard and Barthomeuf 1999; Toghyani et al. 2012; Ashraf et al. 2019; Elghobashy et al. 2020). In the present study, growth performance of commercial broiler birds was evaluated by monitoring the weekly weight gains and feed consumption ratios. In comparison to control, all experimental groups which were given mushroom extracts revealed significantly higher $(P<$ 0.05 ) weight gains. However, in birds of groups given polysaccharide extracts (PSE), highest gains in the weight and FCR were observed in comparison to hot water extracts (HWE) and methanolic extracts (ME). Additionally, during comparison of different species of mushrooms, L. edodes (LO) showed highest values of 
gains in the weights and FCR followed by $P$. sajor-caju (PSC) and $P$. ostreatus (PO), respectively. These encouraging results of weight gains and FCR in mushrooms extracts administered chickens are pinpointing that feed utilization in these groups was relatively better as compared to control group. These results agree with the findings of another study in which broilers when supplemented with $L$. edodes and Tremella fuciformis revealed statistically significant values of weight gains and lesser conversion ratios of feed as compared to those experimental groups which were not supplemented with mushroom extracts. Moreover, values of feed conversions were lower in groups given $L$. edodes supplementation showed lower FCR than Tremella fuciformis administered birds (Guo et al. 2004). Similar findings were reported in other studies in which Agaricus bisporous, L. edodes and Fomitella fraxinea were supplemented (Guo et al. 2003; Dalloul et al. 2006). However, Daneshmand and his co workers in 2011 reported that inclusions of mushrooms alone in the feed had no promotional effects on the production performance, nevertheless if given with probiotics better growth performance can be achieved. Further, it was suggested that the differences observed may be due to the differences of structure, physical characteristics, sugar composition, molar ratios and geographical distribution of mushrooms belonging to different parts of the world. Nevertheless, current study results may suggest that HWE, ME and PSE of PO, PSC and LE can be used as production enhancer in commercial poultry farming.

In this study, post experimental Eimeria infection of all the groups, gains in the weight of birds from day $4^{\text {th }}$ to $12^{\text {th }}$ was recorded and found significantly higher $(P<0.05)$ in groups given different mushroom extracts than the birds of control groups. Among the different extracts, ME revealed highest gains in weights followed by HWE and PSE. Among the different mushrooms (LE) showed highest gains in weights after Eimeria infection followed by PSC and PO. During the experiment, all groups of chickens were also observed for general behaviour, attitude and health status. Birds belonging from control groups were emaciated, weak and lethargic with ruffled feathers and were slow to choose and pick feed particles and water. However, birds which were given different extracts of mushroom species were active and approach the feed anxiously and similar trend was also observed in the consumption of drinking water among different experimental groups. These changes in the behaviour of different groups may be due to variation in the intestinal homeostasis and ultimately causing variations in bird metabolism followed by lowered weight gains and reduced feed intake (Fernando and McCraw 1973; Adams et al. 1996; Pan and Yu 2014).

\section{Conclusion}

The study concludes that mushroom species including $P$. ostreatus, L. edodes and P. sajor-caju have potential to improve the production parameters of broiler birds in healthy animals. Moreover, above mentioned mushrooms can also be used with excellent production results in birds suffering from Eimeria infection.

\section{Acknowledgements}

Funds for this project were sponsored by Higher Education Commission (HEC), Islamabad, Pakistan under the scheme of $\mathrm{PhD}$ indigenous scholarship Batch $\mathrm{V}$ already enrolled PhDs Pin No. 085-12327-Av5-22.

\section{Author Contributions}

MIU, MA and MMA planned the experiment, MIU \& MIA contributed equally in experimentation and interpreted the results, KK and NI finalized the write up.

\section{Conflict of Interest}

The authors declares no conflict of interest

\section{Data Availability}

Data is available

\section{Ethical Approval}

All procedures performed in studies were in accordance with the ethical committee of University of Agriculture.

\section{References}

Abbas RZ, A Abbas, Z Iqbal, MA Raza, K Hussain, T Ahmed, MU Shafi (2020). In vitro anticoccidial activity of Vitis vinifera extract on oocysts of different Eimeria species of broiler chicken. J Hellenic Vet Med Soc 71:2267-2272

Adams CH, A Vahl, A Veldman (1996). Interaction between nutrition and Eimeria acervulina infection in broiler chickens: Development of an experimental infection model. Brit J Nutr 75:867-873

Adhikari PA, WK Kim (2017). Overview of prebiotics and probiotics: Focus on performance, gut health and immunity-a review. Ann Anim Sci 17:949-966

Angelakis E, V Merhej, D Raoult (2013). Related actions of probiotics and antibiotics on gut microbiota and weight modification. Lancet Infect Dis 13:889-899

Ashraf S, SA Bhatti, H Nawaz, MS Khan (2019). Assessment of dietary selenium sources in commercial male broiler breeders: Effects on semen quality, antioxidant status and immune responses. Pak Vet $J$ 39:13-18

Cowieson AJ, AM Kluenter (2019). Contribution of exogenous enzymes to potentiate the removal of antibiotic growth promoters in poultry production. Anim Feed Sci Technol 250:81-92

Dalloul RA, HS Lillehoj, JS Lee, SH Lee, KS Chung (2006). Immunopotentiation effect of a Fomitella fraxinea-derived lectin on chicken immunity and resistance to coccidiosis. Poult Sci $85: 446-451$

Daneshmand A, GH Sadeghi, A Karimi, A Vaziry (2011). Effect of oyster mushroom (Pleurotus ostreatus) with and without probiotic on growth performance and some blood parameters of male broilers. Anim Feed Sci Technol 170:91-96

Dharma M, S Tomar (2007). Role of pro-biotic in improving feed efficiency in poultry. Ind J Indigen Med 11:72 
Elghobashy KA, MM Eldanasoury, AA Elhadary, M Farid (2020). Phytochemical constituent, HPLC profiling and antioxidant activity of Passiflora incarnata and Arctium lappa leaves extracts. Intl J Vet Sci 9:42-49

Fernando MA, BM McCraw (1973). Mucosal morphology and cellular renewal in the intestine of chickens following a single infection of Eimeria acervulina. J Parasitol 59:493-501

Gargano ML, LJ van Griensven, OS Isikhuemhen, U Lindequist, G Venturella, SP Wasser, GI Zervakis (2017). Medicinal mushrooms: Valuable biological resources of high exploitation potential. Plant Biosyst Intl J Deal Asp Plant Biol 151:548-565

Ghorai S, SP Banik, D Verma, S Chowdhury, S Mukherjee, S Khowala (2009). Fungal biotechnology in food and feed processing. Food Res Intl 42:577-587

Grizard D, C Barthomeuf (1999). Non-digestible oligosaccharides used as prebiotic agents: Mode of production and beneficial effects on animal and human health. Rep Nutr Dev 39:563-588

Guo FC, RP Kwakkel, BA Williams, WK Li, HS Li, JY Luo, MWA Verstegen (2004). Effects of mushroom and herb polysaccharides, as alternatives for an antibiotic, on growth performance of broilers. Brit Poult Sci 45:684-694

Guo FC, BA Williams, RP Kwakkel, MW Verstegen (2003). In vitro fermentation characteristics of two mushroom species, an herb, and their polysaccharide fractions, using chicken cecal contents as inoculum. Poult Sci 82:1608-1615

Hazrati S, V Rezaeipour, S Asadzadeh (2020). Effects of phytogenic feed additives, probiotic and mannan-oligosaccharides on performance, blood metabolites, meat quality, intestinal morphology, and microbial population of Japanese quail. Brit Poult Sci 61:132-139

Khater HF, H Ziam, A Abbas, RZ Abbas, MA Raza, K Hussain, EZ Younis, IT Radwan, A Selim (2020). Avian coccidiosis: Recent advances in alternative control strategies and vaccine development. Agrobiol Rec 1:11-25

Lillehoj HS, W Min, RA Dalloul (2004). Recent progress on the cytokine regulation of intestinal immune responses to Eimeria. Poult Sci 83:611-623

Mumtaz S, M Akhtar, MM Awais, MI Anwar (2021). Evaluation of immunomodulatory, growth promoting and protective effects of Ficus religiosa against coccidiosis in broilers. Pak J Agric Sci $58: 219-228$

Pan D, Z Yu (2014). Intestinal microbiome of poultry and its interaction with host and diet. Gut Microb 5:108-119
Salim HM, KS Huque, KM Kamaruddin, BA Haque (2018). Global restriction of using antibiotic growth promoters and alternative strategies in poultry production. Sci Progr 101:52-75

Stanley VGYM, YM Park, C Grayland, WF Krueger (1997). Effects of mannanoligosaccharide (MOS) on aflatoxicosis, serum liver, egg cholesterol and egg production in chickens. In: International Symposium on Non-Digestible Oligosaccharides, p:49. Hartemink R (Ed). Healthy Food for the Colon. Wageningen, The Netherlands

Toghyani M, M Tohidi, A Gheisari, A Tabeidian, M Toghyani (2012). Evaluation of oyster mushroom (Pleurotus ostreatus) as a biological growth promoter on performance, humoral immunity, and blood characteristics of broiler chicks. J Poult Sci 49:183-190

Ullah MI, M Akhtar, MM Awais, MI Anwar, K Khaliq (2018a). Immunological and anti-eimeria effects of hot water and methanolic extracts of Pleurotus sajor-caju in broiler. Kafkas Univ Vet Fak Derg 24:893-898

Ullah MI, M Akhtar, MM Awais, MI Anwar, K Khaliq (2018b). Evaluation of immunostimulatory and immunotherapeutic effects of tropical mushroom (Lentinus edodes) against eimeriasis in chicken. Trop Anim Health Prod 50:97-104

Ullah MI, M Akhtar, Z Iqbal, M Shahid, MM Awais (2015). Immunomodulating and antiprotozoal effects of different extracts of the oyster culinary-medicinal mushroom Pleurotus ostreatus (Higher basidiomycetes) against coccidiosis in broiler. Intl J Med Mushr 17:309-317

Ullah MI, M Akhtar, Z Iqbal (2014). Immunotherapeutic activities of mushroom derived polysaccharides in chicken. Intl J Agric Biol 16:269-276

Willis WL, DC Wall, OS Isikhuemhen, JN Jackson, S Ibrahim, SL Hurley, F Anike (2013). Effect of level and type of mushroom on performance, blood parameters and natural coccidiosis infection in floor-reared broilers. Open Mycol J 7:1-6

Willis WL, DC Wall, OS Isikhuemhen, S Ibrahim, RC Minor, J Jackson, F Anike(2012). Effect of different mushrooms fed to Eimeria-challenged broilers on rearing performance. Intl J Poult Sci 11:433-437

Willis WL, K King, OS Iskhuemhen, SA Ibrahim (2009). Administration of mushroom extract to broiler chickens for bifidobacteria enhancement and Salmonella reduction. J Appl Poult Res 18:658-664

Yasmin S, M Nawaz, AA Anjum, K Ashraf, MAR Basra, A Mehmood, I Khan, F Malik (2020). Phytochemical analysis and In Vitro activity of essential oils of selected plants against Salmonella enteritidis and Salmonella gallinarum of poultry origin. Pak Vet J 40:139-144 